\title{
Seroprevalence and risk factors associated with Helicobacter pylori infection among children aged less than 18 years old in Duhok Province, Iraq
}

\author{
Azad Mohammed Taher Al-Brefkani1, Ibrahim A. Naqid2, , Nizar Bakir Yahya³, Nawfal R. Hussein²
}

\author{
'Department of Medical Lab Technology, Shekhan Technical College of Health, Duhok Polytechnic University, Duhok, Kurdistan Region, Iraq \\ 2Department of Biomedical Sciences, College of Medicine, University of Zakho, Kurdistan Region, Iraq \\ ${ }^{3}$ Department of Paediatric, College of Medicine, University of Duhok, Kurdistan Region, Iraq \\ Correspondence to: Ibrahim A. Naqid (Email: ibrahim.naqid@uoz.edu.krd) \\ (Submitted: 13 March 2021 - Revised version received: 28 April 2021 - Accepted:02 May 2021 - Published online: 26 June 2021)
}

\begin{abstract}
Objectives This study aimed to detect the prevalence of $H$. pylori infection and identify potential factors sociated with infection in Duhok province, Iraq.

Methods This cross-sectional study was conducted in Duhok Province, Kurdistan Region, Iraq. Over a four-year period from 2016 to 2020, a total of 381 children aged four to 18 years who attended the hospitals and were evaluated for specific lgG antibodies against $H$. pylori using serological tests were included. A questionnaire was completed at the start of the study. H. pylori serology data were analyzed using the chi-square test.

Results The seroprevalence of H. pylori lgG-specific antibodies among the study participants was 31\%. The infection rate significantly increased with increasing age of the participants $(P<0.001)$, from $19.8 \%$ among four to five-year-olds to $42.9 \%$ among 16 and 18 -yearolds. The infection rate was significantly higher in girls (35.9\%) than that in boys $(26.5 \%)(P<0.047)$. Infections were also higher among university students (41\%; $P<0.001$ ), children from the country-side population (41\%; $P<0.001)$, children from crowded households (67.3\%; $P<0.001)$, and children with a history of gastrointestinal pain (44.4\%; $P>0.001)$.

Conclusion The prevalence rate of $\mathrm{H}$. pylori infection among children in Duhok province is quite similar to that reported in previous tudies in the Kurdistan region, Iraq, and increases with age. University ttendance, history of gastrointestinal pain, countryside population, and overcrowding were risk factors associated with $\mathrm{H}$. pylori infection. Valuable approaches to improve sanitary purposes and educational and socioeconomic status should be emphasized and promoted to reduce the risk of H. pylori infection among children.

Keywords H. pylori, seroprevalence, risk factors, children, Duhok, Iraq
\end{abstract}

\section{Introduction}

Helicobacter pylori (H. pylori) is a spiral, gram-negative bacterium that is recognized as a worldwide problem. It colonizes the human stomach in approximately half of the world's population and can cause gastritis and peptic ulceration. ${ }^{1,2}$ Infection with this microorganism plays an essential role in the pathogenesis of gastric adenocarcinoma (GA) and primary gastric lymphoma in adulthood. ${ }^{3}$ GA is the second most common cause of cancer-related deaths worldwide. $^{4}$

In a previous study conducted in Iraq, the prevalence of $H$. pylori infection varied according to age group, ranging from $27 \%$ in children to $58 \%$ in teenagers. ${ }^{5}$ In the same study, the infection rate was $78 \%$, which was significantly higher than the prevalence in children. ${ }^{5}$ Several studies have described a significant variation in the seroprevalence of $H$. pylori infection between and within countries due to differences in ethnicity and geographical settings of each population. ${ }^{6}$ It was previously proposed that the acquisition of infection with $H$. pylori occurs during early childhood; adults may carry the same bacterial strain for consecutive decades. ${ }^{7,8}$ It has been previously shown that the prevalence of $H$. pylori infection increases significantly with age, which is largely due to a birth cohort effect rather than a late acquisition of infection. ${ }^{5}$ Additionally, previous report linked $H$. pylori infection with low socioeconomic status, crowded or poor living conditions, low education level or quality of drinking water, and inadequate sanitation practices. ${ }^{9}$
Studies of seroprevalence and the determination of potential risk factors associated with $H$. pylori infection are essential in establishing appropriate health strategies for preventing $H$. pylori-related diseases in the community. Therefore, the present study aimed to evaluate the potential risk factors associated with the seroprevalence rate of $H$. pylori infection among individuals aged 18 years and younger in Duhok province, Kurdistan region, Iraq.

\section{Materials and Methods}

\section{Study design and population}

This cross-sectional study was conducted at the Heevi and Azadi Teaching Hospital and Shekhan Hospital, Kurdistan Region, Iraq. Over a four-year period (2016-2020), a total of 381 blood samples were collected randomly from children aged four to 18 years and evaluated for specific IgG antibodies against $H$. pylori. Information about sociodemographic characteristics including age, gender, hygienic practices, sources of drinking water, education level of parents, accommodation, smoking status, number of family members, family income history of gastrointestinal diseases, and frequency of eating fast food and French fries obtained from each subject after obtaining consent using the questionnaire. All subjects were invited to answer the questionnaire through a face-to-face interview, which was the same as in a previous study. ${ }^{10}$ 


\section{Inclusion and exclusion criteria}

All patients who attended the Heevi and Azadi Teaching Hospital and whose guardians agreed were included in this study. Patients who did not agree to participate were excluded. Other exclusion criteria included a self-reported history of H. pylori-positivity and other gastric disorders.

\section{Serological detection of anti-H. pylori IgG}

A 5-mL syringe and needle were used to bleed about $5 \mathrm{~mL}$ of blood from each subject under aseptic conditions. The blood samples were then centrifuged at $1500 \mathrm{rpm}$ for $5 \mathrm{~min}$ to obtain the serum and kept frozen at $-20^{\circ} \mathrm{C}$ until required. AntiH. pylori IgG positivity was determined using a commercial kit (Bioactiva Diagnostica, Germany) following the manufacturer's instructions. The cut-off was determined by an index value obtained from the ratio of sample absorbance to the absorbance of a cut-off calibrator. The result was considered negative if the $H$. pylori IgG index was $<0.90$, and positive if the $H$. pylori IgG index was $>1.00$.

\section{Ethics approval}

The study was approved by the ethics committee of the College of Medicine, University of Zakho, Kurdistan Region of Iraq, based on the ethical principles of human research and experimentation. Informed consent was obtained from the children's parents or legal guardians before enrollment in the study.

\section{Statistical analysis}

Statistical analysis was performed using SPSS (SPSS, Inc., Cary, NC, USA). To investigate the risk factors for $H$. pylori seropositivity and influential factors, the Chi-square test was used. A significance level of $P<0.05$ was used for all analyses.

\section{Results}

The sociodemographic variables associated with the seroprevalence of $H$. pylori infection in children aged less than 18 years are presented in Table 1. During the study period, 381 (200 girls, 181 boys) were tested for H. pylori-specific IgG. The ages of the participants ranged from four to 18 years. The seroprevalence of $H$. pylori IgG-specific antibodies was 118 (31.0\%). The seroprevalence rate of $H$. pylori according to age varied from $19.8 \%$ in the age group of four to six years to $42.9 \%$ in the age group of 16 to 18 years. There was a positive association between age and seroprevalence; older age had a higher prevalence rate of $H$. pylori IgG antibodies $(P<0.001)$. The seropositivity of $H$. pylori was significantly associated between male (26.5\%) and female (35.9\%) participants $(P<0.047)$. According to the students' education level, the highest seropositivity was found among university students (44.4\%) and the lowest at the pre-school level (20\%), with statistically significant differences $(P<0.001)$. In addition, infection prevalence was significantly higher in the country-side population $(41.0 \%)$ than that in the city population $(25.2 \%)(P<0.001)$. There was also a significant association between the fathers' education levels and $H$. pylori positivity $(P<0.039)$, while no association was found between the mothers' education levels and H. pylori positivity $(P>0.31)$. No significant relationships were found between sources of drinking water $(P>0.52)$, frequency of

\begin{tabular}{|c|c|c|c|c|c|}
\hline \multirow[b]{2}{*}{ Demographic data } & \multicolumn{2}{|c|}{ H. pylori infection (№. [\%]) } & \multirow[b]{2}{*}{ Total } & \multirow[b]{2}{*}{$\chi^{2}$} & \multirow[b]{2}{*}{$P$ value } \\
\hline & $\begin{array}{l}\text { Positive } \\
n=118 \\
(31.0 \%)\end{array}$ & $\begin{array}{c}\text { Negative } \\
n=263 \\
(69.0 \%)\end{array}$ & & & \\
\hline \multicolumn{6}{|l|}{ Age (Year) } \\
\hline $4-6$ & $26(19.8 \%)$ & $105(80.2 \%)$ & 131 & 16.61 & 0.002 \\
\hline $7-9$ & $9(29.0 \%)$ & $22(71.0 \%)$ & 31 & & \\
\hline $10-12$ & $14(26.9 \%)$ & 38 (73.1\%) & 52 & & \\
\hline $13-15$ & $30(39.5 \%)$ & $46(60.5 \%)$ & 76 & & \\
\hline $16-18$ & $39(42.9 \%)$ & $52(57.1 \%)$ & 91 & & \\
\hline \multicolumn{6}{|l|}{ Gender } \\
\hline Boys & $53(26.5 \%)$ & $147(73.5 \%)$ & 200 & 3.93 & 0.047 \\
\hline Girls & $65(35.9 \%)$ & $116(64.1 \%)$ & 181 & & \\
\hline \multicolumn{6}{|c|}{ Education qualification of students } \\
\hline Pre-School & $20(20.0 \%)$ & $80(80.0 \%)$ & 100 & 21.63 & 0.001 \\
\hline Primary School & $21(21.0 \%)$ & 79 (79.0\%) & 100 & & \\
\hline Secondary School & $38(42.2 \%)$ & $52(57.8 \%)$ & 90 & & \\
\hline High School & $35(42.7 \%)$ & $47(57.3 \%)$ & 82 & & \\
\hline University & $4(44.4 \%)$ & $5(55.6 \%)$ & 9 & & \\
\hline \multicolumn{6}{|l|}{ Accommodation } \\
\hline City & $61(25.2 \%)$ & 181 (74.8\%) & 242 & 10.31 & 0.001 \\
\hline
\end{tabular}




\begin{tabular}{|c|c|c|c|c|c|}
\hline \multirow[b]{2}{*}{ Demographic data } & \multicolumn{2}{|c|}{ H. pylori infection (№. [\%]) } & \multirow[b]{2}{*}{ Total } & \multirow[b]{2}{*}{$\chi^{2}$} & \multirow[b]{2}{*}{$P$ value } \\
\hline & $\begin{array}{c}\text { Positive } \\
n=118 \\
(31.0 \%)\end{array}$ & $\begin{array}{c}\text { Negative } \\
n=263 \\
(69.0 \%)\end{array}$ & & & \\
\hline Country side & $57(41.0 \%)$ & $82(95.0 \%)$ & 139 & & \\
\hline \multicolumn{6}{|c|}{ Students father education qualification } \\
\hline Non-literate & $31(34.8 \%)$ & $58(65.2 \%)$ & 89 & 10.1 & 0.039 \\
\hline Primary School & $28(34.6 \%)$ & $53(65.4 \%)$ & 81 & & \\
\hline Secondary School & $27(41.5 \%)$ & $38(58.5 \%)$ & 65 & & \\
\hline High School & $11(21.6 \%)$ & $40(78.4 \%)$ & 51 & & \\
\hline University & $21(22.1 \%)$ & 74 (77.9\%) & 95 & & \\
\hline \multicolumn{6}{|c|}{ Students mother education qualification } \\
\hline Non-literate & $33(34.4 \%)$ & $63(65.6 \%)$ & 96 & 4.73 & 0.31 \\
\hline Primary School & $33(31.1 \%)$ & $73(68.9 \%)$ & 106 & & \\
\hline Secondary School & $30(36.1 \%)$ & $53(63.9 \%)$ & 83 & & \\
\hline High School & $11(25.6 \%)$ & $32(74.4 \%)$ & 43 & & \\
\hline University & $11(20.8 \%)$ & $42(79.2 \%)$ & 53 & & \\
\hline \multicolumn{6}{|c|}{ Source of drinking water } \\
\hline Tape water & $82(32.0 \%)$ & $174(68.0 \%)$ & 256 & 0.41 & 0.52 \\
\hline Mineral water & $36(28.8 \%)$ & $89(71.2 \%)$ & 125 & & \\
\hline \multicolumn{6}{|l|}{ Fast food } \\
\hline Daily & $16(34.8 \%)$ & $30(65.2 \%)$ & 46 & 1.75 & 0.62 \\
\hline Weekly & 39 (28.1\%) & $100(71.9 \%)$ & 139 & & \\
\hline Monthly & $34(35.1 \%)$ & $63(64.9 \%)$ & 97 & & \\
\hline Occasionally & $29(29.3 \%)$ & $70(70.7 \%)$ & 99 & & \\
\hline \multicolumn{6}{|l|}{ Chips and cakes } \\
\hline Daily & $87(32.3 \%)$ & $182(67.7 \%)$ & 269 & 3.2 & 0.36 \\
\hline Weekly & $22(26.8 \%)$ & $60(73.2 \%)$ & 82 & & \\
\hline Monthly & $7(41.2 \%)$ & $10(58.8 \%)$ & 17 & & \\
\hline Occasionally & $2(15.4 \%)$ & $11(84.6 \%)$ & 13 & & \\
\hline \multicolumn{6}{|c|}{ History of gastrointestinal pain in last 3 weeks } \\
\hline Yes & $52(44.4 \%)$ & $65(55.6 \%)$ & 117 & 14.33 & 0.001 \\
\hline No & $66(25.0 \%)$ & $198(75.0 \%)$ & 264 & & \\
\hline \multicolumn{6}{|c|}{ Habit of hand washing before eating } \\
\hline Yes & $68(28.5 \%)$ & $171(71.5 \%)$ & 239 & 1.9 & 0.16 \\
\hline No & $50(35.2 \%)$ & $92(64.8 \%)$ & 142 & & \\
\hline \multicolumn{6}{|c|}{ Washing raw vegetables } \\
\hline Yes & $114(30.4 \%)$ & $261(69.6 \%)$ & 375 & 3.63 & 0.57 \\
\hline No & $4(66.7 \%)$ & $2(33.3 \%)$ & 6 & & \\
\hline \multicolumn{6}{|l|}{ Smoking Status } \\
\hline Yes & $4(30.8 \%)$ & $9(69.2 \%)$ & 13 & 3.86 & 0.145 \\
\hline No & $28(41.2 \%)$ & $40(58.8 \%)$ & 68 & & \\
\hline Not regularly & $7(70.0 \%)$ & $3(30.0 \%)$ & 10 & & \\
\hline \multicolumn{6}{|l|}{ Teeth decay } \\
\hline Yes & $48(31.4 \%)$ & $105(68.6 \%)$ & 153 & 0.019 & 0.89 \\
\hline
\end{tabular}




\begin{tabular}{|c|c|c|c|c|c|}
\hline \multirow[b]{2}{*}{ Demographic data } & \multicolumn{2}{|c|}{ H. pylori infection (№. [\%]) } & \multirow[b]{2}{*}{ Total } & \multirow[b]{2}{*}{$\chi^{2}$} & \multirow[b]{2}{*}{$P$ value } \\
\hline & $\begin{array}{l}\text { Positive } \\
n=118 \\
(31.0 \%)\end{array}$ & $\begin{array}{c}\text { Negative } \\
n=263 \\
(69.0 \%)\end{array}$ & & & \\
\hline No & $70(30.7 \%)$ & $158(69.3 \%)$ & 228 & & \\
\hline \multicolumn{6}{|l|}{ Family income } \\
\hline Very bad & $6(35.3 \%)$ & $11(64.7 \%)$ & 17 & 1.72 & 0.78 \\
\hline Bad & $12(29.3 \%)$ & $29(70.7 \%)$ & 41 & & \\
\hline Middle & $73(32.4 \%)$ & $152(67.6 \%)$ & 225 & & \\
\hline Good & $25(29.1 \%)$ & $61(70.9 \%)$ & 86 & & \\
\hline Very good & $2(16.7 \%)$ & $10(83.3 \%)$ & 12 & & \\
\hline \multicolumn{6}{|c|}{ Number of family members } \\
\hline $2-4$ & $14(23.0 \%)$ & $47(77.0 \%)$ & 61 & & \\
\hline $5-7$ & $36(20.3 \%)$ & $141(79.7 \%)$ & 177 & 45.84 & 0.001 \\
\hline $8-10$ & $31(35.2 \%)$ & $57(64.8 \%)$ & 88 & & \\
\hline$>10$ & $37(67.3 \%)$ & $18(32.7 \%)$ & 55 & & \\
\hline
\end{tabular}

$P$ values were determined using Chi-Square test $\left(\chi^{2}\right)$. $P$ value $<0.05$ were considered statistically significant.

fast food consumption $(P>0.62)$, frequency of eating chips and cakes $(P>0.36)$, and $H$. pylori positivity. The prevalence of $H$. pylori infection was also significantly higher in patients with a history of gastrointestinal pain than that in patients without $(P<0.001)$.

Other potential risk factors such as the habit of handwashing before eating, washing raw vegetables, smoking status, tooth decay, and family income were not statistically associated with $H$. pylori infection. Additionally, a significant association was found between the number of family members with $H$. pylori positivity $(P<001)$; larger families had a higher prevalence rate $(67.3 \%)$.

\section{Discussion}

H. pylori infection is one of the most common chronic infections worldwide; it is estimated that approximately half of the world's population is infected with this pathogen. ${ }^{1,11} H$. pylori infection is a risk factor for gastric ulcer disease and plays a significant role in gastric cancer and gastric lymphoma. ${ }^{4}$ The seroprevalence study and detection of common risk factors for $H$. pylori infection have the potential to underpin appropriate health strategies for preventing $H$. pylori-associated diseases in the community. H. pylori infection has been studied extensively in Iraq; it has been found to be one of the most common infectious agents causing gastric diseases..$^{2,12-15}$ In addition, the prevalence of $H$. pylori infection has been studied in different age groups. ${ }^{5}$ However, no study has determined the other potential risk factors associated with this infection. Therefore, this study examined the seroprevalence of $H$. pylori infection and its associated risk factors.

In this study, the prevalence of $H$. pylori infection was $31.0 \%$ among children aged four to 18 years who attended the Heevi and Azadi Teaching Hospital. Our findings are comparable to those reported in other community-based studies conducted in Sulaimani province, Iraq, where the prevalence of infection was $32.3 \% .{ }^{16}$ In another study conducted in Iraq, the overall seropositivity of $H$. pylori was $36 \%$ in children and $78 \%$ in adults. ${ }^{5}$ Another study also found that $28 \%$ of recruited samples were seropositive for $H$. pylori infection in Duhok Province, Iraq, which is slightly lower than the prevalence reported in our study. ${ }^{17}$ The prevalence of $H$. pylori infection ranges from more than $70 \%$ in developing countries, such as India and Bangladesh, to around $20 \%$ in developed countries, such as Australia and the Netherlands. ${ }^{18}$ However, the prevalence of infection in our study was much lower than that reported in several studies in Iran, where $H$. pylori infection rates were found to be at $47 \%$ to $64 \%{ }^{19}$ and at $72.8 \%{ }^{20}$ Nguyen et al. conducted another study in Langson province, Vietnam, and found an overall seropositivity rate of $41.4 \%$ to $46.8 \%$ in children. ${ }^{21}$ The results of our study were also inconsistent with those of a study conducted in Egypt, Saudi Arabia, and Turkey, where the prevalence rates of $H$. pylori infection were at $60 \%, 75 \%$, and $77.5 \%$, respectively. ${ }^{22,23}$

This study noted possible reasons for this discrepancy in the infection rate between our study and previous reports, which could be due to variations in the studied regions and groups and as well as the laboratory techniques used in the studies. The observed low prevalence in our study could also be the result of frequent usage of antibiotics and proton pump inhibitors or the gradual improvement of socioeconomic status and sanitation during the last decades. ${ }^{24}$ This practice could have led to the increased clearance of $H$. pylori, thereby resulting in lowered prevalence.

Different risk factors are associated with $H$. pylori infection during childhood. Our results showed a significant relationship between $H$. pylori seropositivity and several variables related to socio-demographic characteristics such as age, gender, student and parents' education, accommodation, history of gastrointestinal pain, and number of family members. According to age group, the rate of $H$. pylori infection varied 
from $19.8 \%$ to $42.9 \%$. There was a significant difference between age seroprevalence; older age and those between 16 to 18 years had a higher prevalence rate of $H$. pylori IgG antibodies $(P<0.001)$. Our results are similar to those of a previous study conducted in Iraq, which reported that the prevalence of infection varied according to age, ranging from $27 \%$ in children to $58 \%$ in teenagers. ${ }^{5}$ Another study conducted in Vietnam reported an increase in the seroprevalence of $H$. pylori, from $30.9 \%$ in children under three years to $53.1 \%$ in those 15 to 18 years of age in a study population of 476 children. ${ }^{21}$ Additionally, the highest infection rate was found in girls $(35.9 \%)$, with a statistically significant difference $(P<0.05)$. In contrast to our study, studies from developed countries indicated a higher $H$. pylori infection rate in boys than that in girls. ${ }^{25}$ Other studies conducted in developing countries found that seropositivity rates in men and women seem to be similar. ${ }^{26}$ Gender-specific $H$. pylori seropositivity rates often vary according to the developmental index of the country and its geographic location.

In this study, the highest infection rate of $H$. pylori was found among university students (44.4\%) and the lowest rate at the pre-school level (20\%), with significant differences $(P<0.001)$. This could be due to university students living in dormitories with other students, which could increase the chance of acquiring the infection among themselves. There is also crowding at the universities that increases the chance of person-to-person transmission. Our results are inconsistent with those of a previous study conducted in Duhok province, Iraq, which showed that there were no significant differences between different levels of education. ${ }^{17}$ In a study conducted in Taiwan, lower education levels of mothers were associated with higher $H$. pylori infection rates. ${ }^{27}$ In another study conducted in Russia, a strong positive association between the mothers' education level and $H$. pylori infection rate was observed.$^{28}$ In contrast, in the present study, there was a positive association between the fathers' education level, rather than the mothers', and $H$. pylori infection rate $(P<0.039)$. This could be partly due to the number of samples used in the present study. Further studies are required to recruit a larger number of samples to explore this area.

Additionally, the prevalence rate of $H$. pylori infection was significantly higher in rural areas than in urban areas $(P<0.001)$. This could be due to poor personal, environmental, and residential hygiene conditions, differences in socioeconomic conditions, sources of drinking water, low levels of education, crowded families, and poor residential facilities in rural areas. Public health education on preventable risk factors associated with $H$. pylori infection, such as personal hygiene and sanitation, should be emphasized and promoted in such areas. In this study, $H$. pylori seropositivity was $44.4 \%$ among those with a history of gastrointestinal disease, with a significant difference $(P<0.001)$. Our finding of a positive association between $H$. pylori infection and gastrointestinal disease could be, at least, partly explained by the confounding effects of nutritional habits and several lifestyles accompanying such diseases.

The number of children is the main reason for the increase in household size. Household size, in turn, increases the possibility of $H$. pylori infection. Our study found a lower infection rate of $H$. pylori (20.3\%) among children from households with one to seven members, compared to $67.3 \%$ among children from households with more than 10 members $(P<0.001)$. This could mean that overcrowding increases the chances of acquiring $H$. pylori infection among children. ${ }^{29}$ In large families, children often share their bedrooms or beds with their siblings. Sharing beds can significantly increase the risk of $H$. pylori infection exposure. ${ }^{25}$ The seropositivity rates of $H$. pylori infection are also high in adults living in large households. ${ }^{6,30}$

On the other hand, in the present study, no positive associations were found between the mothers' education levels, habit of hand washing before eating, washing raw vegetables, smoking status, tooth decay, family income, and H. pylori infection. A study conducted in Vietnam found a significant relationship between $H$. pylori seropositivity and several variables related to the socioeconomic status of their household, such as monthly income, mother's education, and father's occupation. ${ }^{31}$ Another study showed that the prevalence of infection was lower in children from families of higher socioeconomic status $(P<0.005){ }^{32}$ The poor socioeconomic status of children in Iran was associated with a higher prevalence of infection $(P<0.005) \cdot{ }^{33}$ Furthermore, a study found that the prevalence of $H$. pylori infection in children without regular hand washing after defecation was significantly higher than in those doing regular hand washing $(P=0.021) .{ }^{31}$ Therefore, our findings disagree with those of previous studies. ${ }^{32,33}$ These differences could be partially due to the number of samples, geographical locations, and techniques used for the detection of infection. Further studies are needed to explore the potential risk factors associated with $H$. pylori infection.

In conclusion, the infection rate of $H$. pylori was found to be $31 \%$ in children aged less than 18 years. This rate is quite similar to other previous studies reported in the Kurdistan region, Iraq, and in neighboring countries. Our data found a low prevalence of $H$. pylori infection among children at an early age; prevalence increases along with increasing age. The highest infection rate was also observed in girls than in boys. Student and parents' education, accommodation, history of gastrointestinal pain, and overcrowding were the risk factors associated with $H$. pylori infection in children. No significant association was found between the habit of handwashing before eating, washing raw vegetables, smoking status, tooth decay, family income, and the rate of $H$. pylori infection. Therefore, effective approaches to improve sanitation and as well as educational and socioeconomic status should be emphasized and promoted to reduce and control $H$. pylori infection.

\section{Acknowledgment}

We would like to thank the staff of Heevi, Azadi Teaching Hospital and Shekhan Hospital for their kind help and support.

\section{Funding/Support}

The authors received no financial support for the publication of this article.

\section{Conflicts of Interest}

The authors declare that there is no conflict of interests. 


\section{References}

1. Hussein NR. Helicobacter pylori and gastric cancer in the Middle East: a new enigma? World J Gastroenterol. 2010;16:3226-34.

2. Hussein NR, Saleem ZS, Balatay AA, Abd KH, Daniel S, Taha AA, et al. Seroprevalence of Helicobacter pylori Infection in Renal Transplant Recipient Attending Duhok Kidney Disease Center. Transplantation proceedings. 2016;48(1):92-5.

3. Ishaq S, Nunn L. Helicobacter pylori and gastric cancer: a state of the art review. Gastroenterology and hepatology from bed to bench. 2015; 8(Suppl 1):S6-S14.

4. Atherton JC. The pathogenesis of Helicobacter pylori-induced gastroduodenal diseases. Annual review of pathology. 2006;1:63-96.

5. Hussein NR, Robinson K, Atherton JC. A study of Age-Specific Helicobacter pylori Seropositivity Rates in Iraq. Helicobacter. 2008;13(4):306-7.

6. Mitchell H, Megraud F. Epidemiology and diagnosis of Helicobacter pylori infection. Helicobacter. 2002;7 Suppl 1:8-16.

7. Malaty HM, El-Kasabany A, Graham DY, Miller CC, Reddy SG, Srinivasan SR, et al. Age at acquisition of Helicobacter pylori infection: a follow-up study from infancy to adulthood. Lancet (London, England). 2002;359(9310):931-5.

8. Kivi M, Johansson AL, Reilly M, Tindberg Y. Helicobacter pylori status in family members as risk factors for infection in children. Epidemiology and infection. 2005;133(4):645-52.

9. Al-Shamahy HA. Seroprevalence of Helicobacter pylori among children in Sana'a, Yemen. Annals of Saudi medicine. 2005;25(4):299-303.

10. Kim JH, Kim HY, Kim NY, Kim SW, Kim JG, Kim JJ, et al. Seroepidemiologica study of Helicobacter pylori infection in asymptomatic people in South Korea. Journal of gastroenterology and hepatology. 2001;16(9):969-75.

11. Go MF. Review article: natural history and epidemiology of Helicobacter pylori infection. Alimentary pharmacology \& therapeutics. 2002;16 Suppl 1:3-15.

12. Hussein NR, Mohammadi M, Talebkhan Y, Doraghi M, Letley DP, Muhammad $M K$, et al. Differences in virulence markers between Helicobacter pylori strains from Iraq and those from Iran: potential importance of regional differences in $\mathrm{H}$. pylori-associated disease. Journal of clinical microbiology. 2008;46(5):1774-9.

13. Hussein NR, Napaki SM, Atherton JC. A study of Helicobacter pyloriassociated gastritis patterns in Iraq and their association with strain virulence. Saudi J Gastroenterol. 2009;15(2):125-7.

14. Salih AM, Goreal A, Hussein NR, Abdullah SM, Hawrami K, Assafi M. The distribution of cagA and dupA genes in Helicobacter pylori strains in Kurdistan region, northern Iraq. Annals of Saudi medicine. 2013;33(3):290-3.

15. Hussein NR, Mirkhan SA, Ramadhan AA, Issa RS, Naqid IA, Yassin B, et al. Levofloxacin-Based Regimen Versus Bismuth Quadruple Regimen for Helicobacter pylori Eradication in Kurdistan Region, Iraq. Avicenna J Clin Microbiol Infect. 2020;7(3):81-4.

16. Bayati A, Al-Windi A, Ahmad N. Seroprevalence of anti-Helicobacter pylori antibodies in population of Sulaimani governorate/Kurdistan Region//raq Journal Zankoy Sulaimani. 2013;15:175-85.

17. Yahya N. Helicobacter pylori Seropositivity in Children in Duhok City, Iraq. Science Journal of University of Zakho. 2018;6:82-7.
18. Khalifa MM, Sharaf RR, Aziz RK. Helicobacter pylori: a poor man's gut pathogen? Gut pathogens. 2010;2(1):2.

19. Falsafi T, Valizadeh N, Sepehr S, Najafi M. Application of a stool antigen test to evaluate the incidence of Helicobacter pylori infection in children and adolescents from Tehran, Iran. Clinical and diagnostic laboratory immunology. 2005;12(9):1094-7.

20. Salehi M, Ghasemian A, Shokouhi Mostafavi SK, Najafi S, Rajabi Vardanjani H. Sero-prevalence of Helicobacter pylori Infection in Neyshabur, Iran, During 2010-2015. Iran J Pathol. 2017;12(2):183-8.

21. Viet T, Nguyen H, Nguyen V, Thanh T, Phan B, Hoang h, et al. Epidemiology of Helicobacter pylori Infection in Tay Children in Vietnam. Annals of Clinical and Laboratory Research. 2016;04.

22. Frenck RW, Jr., Fathy HM, Sherif M, Mohran Z, El Mohammedy H, Francis W, et al. Sensitivity and specificity of various tests for the diagnosis of Helicobacter pylori in Egyptian children. Pediatrics. 2006;118(4):e1195-202.

23. Salih BA. Helicobacter pylori infection in developing countries: the burden for how long? Saudi J Gastroenterol. 2009;15(3):201-7.

24. Egan BJ, Holmes K, O'Connor HJ, O'Morain CA. Helicobacter pylori gastritis, the unifying concept for gastric diseases. Helicobacter. 2007;12 Suppl 2:39-44.

25. Moayyedi P, Axon AT, Feltbower R, Duffett S, Crocombe W, Braunholtz D, et al. Relation of adult lifestyle and socioeconomic factors to the prevalence of Helicobacter pylori infection. Int J epidemiology. 2002;31(3):624-31.

26. Yilmaz E, Doğan Y, Gürgöze MK, Unal S. Seroprevalence of Helicobacter pylori infection among children and their parents in eastern Turkey. J Paediatr Child Health. 2002;38(2):183-6.

27. Wu MC, Sung CH, Chang YC, Ho CL, Wu CC, Wu KH, et al. Seroprevalence of Helicobacter pylori and Hepatitis A Virus among Children in Rural Central Taiwan. Jpn J Infect Dis. 2015;68(6):494-503.

28. Malaty HM, Paykov V, Bykova O, Ross A, Graham DP, Anneger JF, et al. Helicobacter pylori and socioeconomic factors in Russia. Helicobacter. 1996;1(2):82-7.

29. Ding Z, Zhao S, Gong S, Li Z, Mao M, Xu X, et al. Prevalence and risk factors of Helicobacter pylori infection in asymptomatic Chinese children: a prospective, cross-sectional, population-based study. Alimentary pharmacology \& therapeutics. 2015;42(8):1019-26.

30. Fraser AG, Scragg R, Metcalf P, McCullough S, Yeates NJ. Prevalence of Helicobacter pylori infection in different ethnic groups in New Zealand children and adults. Australian and New Zealand journal of medicine. 1996:26(5):646-51.

31. Nguyen V, Nguyen K, Phung C, Kremp O, Kalach N, Dupont C, et al. Prevalence of and factors associated with Helicobacter pylori infection in children in the North of Vietnam. The American journal of tropical medicine and hygiene. 2006;74:536-9.

32. Etukudo OM, Ikpeme EE, Ekanem EE. Seroepidemiology of Helicobacter pylori infection among children seen in a tertiary hospital in Uyo, southern Nigeria. Pan Afr Med J. 2012;12:39-

33. Alborzi A, Soltani J, Pourabbas B, Oboodi B, Haghighat M, Hayati M, et al. Prevalence of Helicobacter pylori infection in children (south of Iran). Diagnostic microbiology and infectious disease. 2006;54(4):259-61. 